\title{
Knowledge and Attitude of School Teachers towards Promoting Healthy Lifestyle to Students
}

\author{
Nga Yee Irene Cheng1, Man Yee Emmy Wong2 \\ ${ }^{1}$ Department of Science and Environmental Studies, The Hong Kong Institute of Education, Hong Kong, China \\ ${ }^{2}$ Department of Early Childhood Education, The Hong Kong Institute of Education, Hong Kong, China \\ Email: emmywong@ied.edu.hk
}

Received 29 December 2014; accepted 12 January 2015; published 19 January 2015

Copyright (C) 2015 by authors and Scientific Research Publishing Inc.

This work is licensed under the Creative Commons Attribution International License (CC BY). http://creativecommons.org/licenses/by/4.0/

(c) (i) Open Access

\begin{abstract}
Teachers play an important role in delivering health education to empower students with skills for healthy living to prevent non-communicable diseases. One of the common non-communicable diseases is hypertension that its development is highly associated with unhealthy lifestyle. A survey was administered to assess 130 pre-service teachers and 54 in-service teachers who were taking the health education course to prepare them for teaching the content of healthy living in Hong Kong. The assessment included their knowledge level of hypertension, attitudes towards lifestyle modification education to students, perception of knowledgeable to give health education. It was found that the knowledge level related to hypertension was generally below average among the teachers. Although they considered that lifestyle modification was an effective way to enhance students' well-being, both pre-service and in-service teachers were reluctant to take responsibility for lifestyle modification education to their students. Lack of skill training was perceived as a problem. Teachers' perception on health education should not be limited to the provision of simple information and advice. There is a need to improve teachers' health literacy on some common non-communicable diseases.
\end{abstract}

\section{Keywords}

Attitude, Knowledge, Health Education, Healthy Lifestyle, Health Literacy

\section{Introduction}

Lifestyle modifications include healthy diet and regular aerobic exercise that are more likely to be successful for 
avoiding non-communicable diseases (NCDs) [1]. In response to the challenge of NCDs induced health problems, the current strategy for primary prevention of NCDs is focused on health education starting from early school life [2]. As the largest group of education providers, teachers play an important role in healthy lifestyle modification education to students [3]. In Hong Kong, the core subject to provide health education for primary level students (Year 1 to 6, aged 6 - 12) is General Studies. This subject integrates the content knowledge of personal, social, humanities education, science education and technology education [4]. Health education is under the "Personal, Social \& Humanities Education" [5]. In secondary school level, Liberal Studies is one of four compulsory subjects to provide health knowledge to Form 4 to Form 6 students (Year 10 to 12, aged 15 - 18) under the new senior secondary (NSS) curriculum. This subject infuses science, humanities and technology in its curriculum. One sixth of this subject content is health related [6]. However, the design of subject content has been criticized as knowledge-based without integrating the skill in health promotion and education [3]. The government efforts on health literacy largely focus on education on health knowledge and project-based programs [7] [8].

The project-based programs have been developed to promote health and well-being of school children so as to increase their capacity for making healthy choices. A health promoting school program has been launched for primary schools and secondary schools since 1998. The program provides a structured framework for promoting the healthy development of school children through various support including health policies, health services, personal health skills, social environment, community relationships and physical environment. It aims at improving the health of students, school personnel, families and other community members through the promotion efforts of the schools [9]. Despite these advances, local health education is reliant heavily on university support. This situation limits schools' ability to autonomously develop this area of the curriculum [3]. Teachers' adequacy in teaching and promoting healthy lifestyle is questionable.

In Hong Kong, four out of eight higher education institutes have offered teacher training programs that are funded by the University Grants Committee (UGC). Among the four higher education institutes, three universities have launched Liberal Studies program and only one UGC funded higher education institute has offered both Liberal Studies and General Studies teacher training. The teaching content of health education for teachers is less than one percent of the whole program and is heavily social oriented in health among the four institutes [10]-[13]. These teacher training programs, mainly designed by faculty members with experience of education, have provided knowledge-based health education with limited skill-based practice.

This study has been designed to assess knowledge and attitude of pre-service and in-service teachers teaching Liberal Studies and General Studies towards promoting healthy lifestyle in light of preventing the most common non-communicable health problem-hypertension. Hypertension has long been recognized as a common NCD that can cause stroke, hypertensive heart disease or coronary artery disease leading to impairment to the quality of life, the development of other chronic diseases and even death worldwide [1] [14]. In 2013, heart diseases (13.4\%) and cerebrovascular diseases (7.5\%) are two of the top five leading causes of death in Hong Kong [15]. The prevalence of hypertension increases with increasing age [16] [17].

The knowledge of in-service and pre-service teachers on hypertension and stroke, their attitudes towards teaching healthy lifestyle modification to students, perceptions of the need to provide lifestyle modification education to students and self-perception of knowledgeability to give lifestyle modification education to students were examined.

\section{Method}

This cross-sectional survey study was conducted from November 2010 to January 2011 in the mentioned UGCfunded tertiary education institute that provided both General Studies and Liberal Studies teacher training in Hong Kong. Approval to conduct this study was obtained from the Ethical Review Board of the Institute.

\subsection{Sample}

All teachers (both in-service and pre-service) taking the health education course of either General Studies or Liberal Studies of Bachelor of Education program were invited to take part in this study. A questionnaire was given to 148 pre-service teachers and 79 in-service teachers. Totally, 130 pre-service teachers and 54 in-service teachers completed and returned the questionnaire that represented $81 \%$ response rate. 


\subsection{Measures}

The questionnaire consisted of four components of measures: 1) demographic information; 2) level of knowledge on hypertension; 3) a series of attitudinal statements and 4) self-perception of knowledgeability to give lifestyle modification education to students. Teachers' level of knowledge on hypertension and stroke was examined by 9 items developed from the health education content materials covered in General Studies and Liberal Studies; and common health knowledge related to predisposing factors, diagnostic criteria and preventive management of hypertension provided by the Department of Health [18]. The information provided by the Department of Health is open to the public and is useful source for teachers to prepare their health education lecture. The scoring system of knowledge of hypertension is " 1 = true”, " 2 = false” and “ 3 = don't know”. Percentage scores for correct answer are calculated.

Attitudes towards lifestyle modification education to students were explored by a 5-item self-developed questionnaire. A 5-point Likert scale was used to measure the teachers' attitudes towards providing advice for healthy lifestyle modification to students. For example, "As an educator, I need to guide my students to have positive lifestyle” and the measure score from 1 (strongly agree) to 5 (strongly disagree). A lower attitudinal score reveals a more positive attitude of teachers regarding the provision of health education advice for healthy lifestyle modification to students. The overall alpha reliability coefficients for these 5 items were 0.75 .

Practice on providing healthy lifestyle modification education was tested by 6 items. The sample questions are "I teach my students to do exercise for at least 3.5 hours every week" and "I teach my students how to make healthy food choices". The measure score ranged from 1 (strongly agree) to 5 (strongly disagree). The overall Cronbach's alpha was 0.86, indicating good internal consistency. A lower score of practice suggests that teachers were more inclined to provide healthy lifestyle modification education to their students.

Perception of knowledgeability to provide healthy lifestyle modification education to students was measured by 3 items in a 5-point Likert scale with the same measure score as attitudes towards lifestyle modification education. For example, "Healthy lifestyle modification education is very effective to enhance my students' positive lifestyle modification". Teachers obtaining lower scores tended to perceive higher levels of self-efficacy in healthy lifestyle counseling. Cronbach's alpha for the 3 items was 0.85 .

Socio-demographic data including the teachers' age, gender, teaching position and nature of schools were also collected.

\subsection{Data Collection}

A pilot test was done by 5 pre-service teachers and 3 in-service teachers to test the language of the questionnaire. Minor changes to the wordings were made to ensure clarity. None of the teachers involved in the pilot study were included in the main study. The study was conducted by self-administrated questionnaire on campus after they had completed a health-related lecture. Information sheet to describe the aim and nature of the study was provided to all teachers via the lecturers. Informed consent was obtained from all participating teachers with a signed consent form indicating willful participation of the study. After signing the consent form, the teachers were invited to fill in the questionnaire. Completed questionnaires were returned to the lecturers in a sealed envelope to safeguard the confidentiality of the teachers.

\subsection{Data Analysis}

Data were analyzed using the chi-square test and unpaired t-tests using SPSS 21 statistical software program [19]. Descriptive analyses were conducted using percentages, means and standard deviation. Bivariate analyses were conducted to examine unadjusted relationships between teachers' knowledge on hypertension and stroke, attitudes towards lifestyle modification education to students, lifestyle modification education practice, perception for the need of lifestyle modification education to students, perception of knowledgeability and easiness to give lifestyle modification education, teachers as an influential person to health education and health promotion and effectiveness of health professionals' advice. Multiple linear regression modeling was applied to elicit the relationships between those independent variables identified from the bivariate analyses and the lifestyle modification education practice. A 5\% significance level was used for the testing.

\section{Results}

In total, 130 pre-service teachers (70.6\%) and 54 in-service teachers (29.4\%) participated in the study. Most 
teachers were below 25 years old (61.4\%). There were more female $(n=100 ; 54.3 \%)$ than male teachers $(n=84$; $45.7 \%)$. The majority of in-service teachers were subject teachers $(70.4 \%)$ and had less than 5 years' teaching experience $(74.1 \%)$ (Table 1$)$.

The teachers' level of knowledge about hypertension was low. Most teachers did not answer correctly that "Elevation of either systolic or diastolic blood pressure can represent hypertension" (75.5\%), "Hereditary plays a major role in the development of hypertension" (76.6\%), and "Hypertension is associated with Type II diabetes" (65.2\%). For the 9 questions related to the knowledge of hypertension and stroke, the correct rates were only $48 \%$ and $53 \%$ respectively. The mean score of the overall attitudes towards lifestyle modification education was $1.73(\mathrm{SD}=0.45)$. The overall practice mean score was $2.01(\mathrm{SD}=0.52)$. The mean score of the perception of the need for lifestyle modification education was $2.16(\mathrm{SD}=0.54)$. However, the teachers did not feel it was easy for them to teach their students about healthy lifestyle (mean $=3.23$, SD $=0.94$ ), were not knowledgeable to give lifestyle modification education (mean $=2.72, \mathrm{SD}=0.87$ ) and they did not perceive themselves as an influential person to change their students' unhealthy lifestyle (mean $=3.04, \mathrm{SD}=0.79$ ). On the other hand, they reflected that involvement of health professionals could be effective in providing lifestyle counseling to the students (mean $=2.09, \mathrm{SD}=0.65$ ) (Table 2). No significant differences in the knowledge, attitude, practice and self-perception of lifestyle modification items were detected between the in-service teachers and pre-service teachers. The results of the two groups of teachers were, therefore, presented in aggregate.

\subsection{Associations with Practice on Healthy Lifestyle Modification Education}

The bivariate relationships between healthy lifestyle modification education to students, their attitudes, knowledge level of hypertension and stroke and other potential perceived variables were examined. The results are summarized in Table 3. Lifestyle modification education practice was significantly positively associated with all variables except knowledge level of hypertension and stroke.

\subsection{Predictors of Teachers' Healthy Lifestyle Modification Education Practice}

The results obtained from regression analyses were presented in Table 4. The regression model explained 37.0\% of the variance while the adjusted $R^{2}$ took into account the number of explanatory variables added. The lifestyle

Table 1. Demographic characteristics of the participants.

\begin{tabular}{|c|c|c|}
\hline & $\mathrm{n}$ & $\%$ \\
\hline \multicolumn{3}{|l|}{ Age (years) $(n=184)$} \\
\hline$\leq 25$ & 113 & 61.4 \\
\hline $26-40$ & 65 & 35.3 \\
\hline $41-55$ & 6 & 3.3 \\
\hline \multicolumn{3}{|l|}{ Gender $(n=184)$} \\
\hline Male & 84 & 45.7 \\
\hline Female & 100 & 54.3 \\
\hline \multicolumn{3}{|c|}{$\begin{array}{l}\text { Teaching experience for in-service teachers } \\
\text { (years) }(\mathrm{n}=54)\end{array}$} \\
\hline$\leq 5$ & 40 & 74.1 \\
\hline $6-10$ & 8 & 14.8 \\
\hline$>10$ & 6 & 11.1 \\
\hline \multicolumn{3}{|c|}{ Position for in-service teachers $(n=54)$} \\
\hline Subject coordinator & 8 & 14.8 \\
\hline Subject teacher & 38 & 70.4 \\
\hline Subject assistant teacher & 8 & 14.8 \\
\hline
\end{tabular}


Table 2. Knowledge, attitude, practice and self-perception of lifestyle modification of the participants $(\mathrm{n}=184)$.

\begin{tabular}{lcc}
\hline & Mean & SD \\
\hline Knowledge level of hypertension & 0.48 & 0.22 \\
Knowledge level of stroke & 0.53 & 0.33 \\
Attitudes towards lifestyle modification education & 1.73 & 0.45 \\
Lifestyle modification education practice & 2.01 & 0.52 \\
Perception of the need of lifestyle modification education to students & 2.16 & 0.54 \\
I am knowledgeable to give lifestyle modification education & 2.72 & 0.87 \\
It is easy to teach my students about a healthy lifestyle & 3.23 & 0.94 \\
Teachers are influential in educating students to change their negative lifestyle & 3.04 & 0.79 \\
Health professionals are effective in providing lifestyle counseling to students & 2.09 & 0.65 \\
\hline
\end{tabular}

SD: standard deviation.

Table 3. Bivariate association between lifestyle modification education practice and other potential variables.

\begin{tabular}{|c|c|c|c|c|c|c|c|c|}
\hline & Var 1 & Var 2 & Var 3 & Var 4 & Var 5 & Var 6 & Var 7 & Var 8 \\
\hline \multicolumn{9}{|l|}{ Var 1: Knowledge level of hypertension } \\
\hline Var 2: Knowledge level of stroke & $0.389^{* *}$ & & & & & & & \\
\hline Var 3: Attitude toward lifestyle modification education & $-0.151^{*}$ & $-0.206^{* *}$ & & & & & & \\
\hline Var 4: Lifestyle modification education practice & -0.122 & -0.143 & $0.475^{* *}$ & & & & & \\
\hline Var 5: Need of lifestyle modification education & -0.112 & -0.143 & $0.324^{* *}$ & $0.434^{* *}$ & & & & \\
\hline Var 6: Knowledgeable to give health education & $-0.187^{*}$ & $-0.176^{*}$ & $0.149^{*}$ & $0.320^{* *}$ & $0.186^{*}$ & & & \\
\hline Var 7: Easiness to teach & 0.101 & 0.040 & -0.117 & $0.184^{*}$ & $0.185^{*}$ & $0.232^{* *}$ & & \\
\hline Var 8: Teachers as an influential person & -0.005 & 0.069 & 0.124 & $0.327^{* *}$ & $0.297^{* *}$ & $0.229^{* *}$ & $0.413^{* * *}$ & \\
\hline Var 9: Effectiveness of health professionals' advice & 0.009 & -0.095 & $0.359^{* *}$ & $0.268^{* *}$ & $0.413^{* *}$ & 0.053 & 0.102 & $0.249^{* *}$ \\
\hline
\end{tabular}

Table 4. Linear regression of healthy lifestyle modification education practice.

\begin{tabular}{lcc}
\hline & $\beta$ & t-value (Sig) \\
\hline Attitude toward lifestyle modification education & 0.361 & 5.329 \\
Need of lifestyle modification education & 0.231 & 3.377 \\
Knowledgeable to give health education & 0.176 & 2.810 \\
Easiness to teach & 0.093 & 1.375 \\
Teachers as an influential person & 0.141 & 2.079 \\
Effectiveness of health professionals' advice & -0.018 & 0.001 \\
\hline
\end{tabular}

$\beta=$ standardized coefficients; $R^{2}=0.394 ;$ Adj $R^{2}=0.370$.

modification education practice was significantly related to overall attitudes ( $\beta=0.361 ; p<0.001$ ), perception of the needs of lifestyle modification education to students $(\beta=0.231 ; p=0.001)$ and perception of their knowledgeability to give health education $(\beta=0.176 ; p=0.006)$.

\section{Discussion}

The present study described the knowledge level and attitude of teachers towards promoting healthy lifestyle to students. As a health promotion model proposed by Nutbeam [20], practice and health promotion skills of health 
educators are important elements to guide the students to cultivate healthy lifestyle. In this study, the teachers perceived that there was a need to provide lifestyle modification education to their students. However, they did not see themselves as influential person to promote healthy lifestyle. Although they were the ones to teach health related content, they did not perceive themselves as being knowledgeable to give lifestyle modification education to their students. They also reflected that health professionals were effective in providing health education to students. This demarcation of roles has also been observed in other studies [21]-[23]. Among the variables, attitude was the key variable to predict their healthy lifestyle modification education practice.

With regards to the teachers' attitude towards health education, studies show that teachers who have experienced health promotion training tend to be involved more frequently in health promotion practice and have a more comprehensive approach to health education [24]. Different from the existing teaching pedagogy in the other subjects, teacher training in health education should not view health as an end product but part of education for sustainable development. It is important to indicate that health promotion and education is a way to improve health and to help students succeed in education. Teachers should receive specific types of education to ensure the sustainable development in health education and promotion and they have a specific role to play instead of the prevalent "fragmented" type of health related teacher training program. Further study is needed to explore the various dimensions of training.

With regards to the teachers' knowledge on health education, this study indicated that the teachers' knowledge levels of hypertension and stroke were generally low under current teacher training and professional development training. The phenomenon of lacking basic knowledge about common NCDs was highly persistent in both pre-service and in-service teachers. The content of the teacher training curriculum in health literacy for both teacher training and professional development programs have rooms for improvement. There is a need to review the current education curriculum and the methods to be used in training health and well-being of teachers [3] and further planning for the appropriate content and methods of health education.

With regards to the support in the improvement of skill training, some teachers feel that health education is not perceived as the core element of teaching among the majority of works in schools in Hong Kong. Health education is non-subject based in Hong Kong school curriculum and is often seen as peripheral to the main subjects such as Chinese and English languages, and Mathematics. To these teachers, health education should be handled in the area of public health field, but not in the education system [25]. However, the issues of high risk behavior and the preventable NCDs are increasing rapidly worldwide, and teachers are facing the challenge of their contribution to health education [3] [25] with the societal demands on schools to promote healthy living and well-being. The obstacle to this effort may be the lack of recognition or attempt to integrate the knowledge and skills in classroom teaching of health education that goes beyond the curriculum's subject knowledge [5] [6]. Taking into account of the teachers' belief on their own role in health education as indicated in this study, health professionals should be called upon to contribute to health education in teacher training. They should share a common store of knowledge that can empower teachers to contribute substantially and explicitly in school health education [25]. Further study on the collective beliefs of teachers and health professionals about what schools should be doing in the area of health education needs to be conducted to examine how support could be provided for the improvement of skills in health education.

The study has some limitations concerning the recruitment of participants. First, the sample could not cover all ranks of in-service teachers and most of the teachers had less than five years teaching experience. Hence, the results of the study could only be partially applied to a group of pre-service and in-service teachers. Second, this was a cross-sectional study that was difficult to make causal inferences. Third, although the coefficients of the questionnaire reached over 0.7 of a moderate degree, further validation of this newly developed questionnaire is needed to ensure its accuracy. Fourth, knowledge level of NCDs other than hypertension and stroke was not assessed in this study. Future study could be done to fill this research gap.

\section{Conclusion}

This study aims to examine the knowledge level and attitude of school teachers towards promoting healthy lifestyle to students. The knowledge level was generally low. Teachers' attitude towards lifestyle modification education was not strong. Overall, this study highlights several practical issues that need to be addressed. Multiple tensions may affect teachers' health education training to provide lifestyle modification education to students. There is a need to re-examine the health education curriculum and pedagogy in teacher training. Health profes- 
sionals can have more contributions on the design of the health education elements in the school curriculum and teacher training curriculum and its related teaching method.

\section{References}

[1] Nicoll, R. and Henein, M.Y. (2010) Hypertension and Lifestyle Modification: How Useful Are the Guidelines? British Journal of General Practice, 60, 879-880. http://dx.doi.org/10.3399/bjgp10X544014

[2] Jones, C.A., Mawani, S., King, K.M., Allu, S.O., Smith, M., Mohan, S. and Campbell, N.R. (2011) Tackling Health Literacy: Adaptation of Public Hypertension Educational Materials for an Indo-Asian Population in Canada. BMC Public Health, 11, 1-11. http://dx.doi.org/10.1186/1471-2458-11-24

[3] Wong, E.M.Y. and Cheng, M.M.H. (2012) Priorities for Health Education in Hong Kong in Relation to Non-Communicable Diseases. In: Taylor, N., Quinn, F., Littledyke, M. and Coll, R.K., Eds., Health Education in Context: An International Perspective on the Development of Health Education in Schools and Local Communities, Sense Publishers, The Netherlands, 211-221. http://dx.doi.org/10.1007/978-94-6091-876-6_23

[4] Curriculum Development Council (2011) General Studies for Primary Schools Curriculum Guide (Primary 1 - Primary 6).

http://www.edb.gov.hk/attachment/en/curriculum-development/kla/general-studies-for-primary/gs p guide-eng 300dp i-final\%20version.pdf

[5] Curriculum Development Council (2002) Personal, Social \& Humanities Education: Key Learning Area Curriculum Guide (Primary 1 - Secondary 3).

http://www.edb.gov.hk/attachment/en/curriculum-development/kla/pshe/PSHE\%20KLA\%20Guide\%20Eng.pdf

[6] Curriculum Development Council and Hong Kong Examinations and Assessment Authority (2007) Liberal Studies: Curriculum and Assessment Guide (Secondary 4 - 6).

http://ls.edb.hkedcity.net/LSCms/file/web_v2/C_and_A_guide/201401/LS\%20C\&A\%20Guide_updated_e.pdf

[7] Wong, E.M.Y. and Cheng, M.M.H. (2013) Effects of Motivational Interviewing to Promote Weight Loss in Obese Hong Kong Children. Journal of Clinical Nursing, 22, 2519-2530. http://dx.doi.org/10.1111/jocn.12098

[8] Lee, A., Cheng, F.F.K., Fung, Y. and St Leger, L. (2006) Can Health Promoting Schools Contribute to the Better Health and Wellbeing of Young People? The Hong Kong Experience. Journal of Epidemiol Community Health, 60, 530-536. http://dx.doi.org/10.1136/jech.2005.040121

[9] Lee, A., Cheng, F.F.K. and St Leger, L. (2005) Evaluating Health-Promoting Schools in Hong Kong: Development of a Framework. Health Promotion International, 20, 177-186. http://dx.doi.org/10.1093/heapro/dah607

[10] Faculty of Education, The University of Hong Kong (2014) Bachelor of Education. http://web.edu.hku.hk/current-students/tpg-ug-programmes/undergraduate-programmes-for-hkale-cohorts/HKALE-bes $\underline{\text { libst }}$

[11] Faculty of Education, The Chinese University of Hong Kong (2014) Liberal Studies: Applicable to Students Admitted in 2014-15 (5-Year Curriculum). http://www.fed.cuhk.edu.hk/ lse/studyschemes/LSED_ENG_14_HKDSE.pdf

[12] Department of Education Studies, Hong Kong Baptist University (2014) Bachelor of Arts (Hons) in History and Bachelor of Education (Hons) in Liberal Studies Teaching. http://educ.hkbu.edu.hk/?page_id=144

[13] Faculty of Liberal Arts and Social Sciences, The Hong Kong Institute of Education (2014) Bachelor of Education (Honours) (Primary) Programme (Five-Year Full-Time). http://www.ied.edu.hk/flass/fas_upload/userfiles/file/2ndMajorMinor_leaflet.pdf

[14] Longo, D., Fauci, A., Kasper, D., Hauser, S., Jameson, J. and Loscalzo, J. (2011) Harrison’s Principles of Internal Medicine. McGraw Hill Professional, New York.

[15] Centre for Health Protection, Department of Health (2014) Vital Statistics: Number of Deaths by Leading Causes of Death by Sex by Age in 2013. http://www.chp.gov.hk/en/data/4/10/27/340.html

[16] Burt, V.L., Whelton, P., Roccella, E.J., Brown, C., Cutler, J.A., Higgins, M. and Labarthe, D. (1995) Prevalence of Hypertension in the US Adult Population Results from the Third National Health and Nutrition Examination Survey, 1988-1991. Hypertension, 25, 305-313. http://dx.doi.org/10.1161/01.HYP.25.3.305

[17] Ma, W.J., Tang, J.L., Zhang, Y.H., Xu, Y.J., Lin, J.Y., Li, J.S. and Ignatius, T.S. (2012) Hypertension Prevalence, Awareness, Treatment, Control, and Associated Factors in Adults in Southern China. American Journal of Hypertension, 25, 590-596. http://dx.doi.org/10.1038/ajh.2012.11

[18] Centre for Health Protection, Department of Health (2012) Non Communicable Diseases and Risk Factors. http://www.chp.gov.hk/en/health_topics/9/25.html

[19] IBM Corp. (2011) IBM SPSS Statistics for Windows, Version 20.0. IBM Corp., Armonk, New York. 
[20] Nutbeam, D. (2000) Health Literacy as a Public Health Goal: A Challenge for Contemporary Health Education and Communication Strategies into the 21st Century. Health Promotion International, 15, 259-267. http://dx.doi.org/10.1093/heapro/15.3.259

[21] Jourdan, D., McMamara, P.M., Simar, C., Geary, T. and Pommier, J. (2010) Factors Influencing the Contribution of Staff to Health Education in Schools. Health Education Research, 25, 519-530. http://dx.doi.org/10.1093/her/cyq012

[22] Yu, X., Yang, T., Wang, S. and Zhang, X. (2012) Study on Student Health Literacy Gained Through Health Education in Elementary and Middle Schools in China. Health Education Journal, 71, 452-460. http://dx.doi.org/10.1177/0017896911430548

[23] Wong, E.M.Y., Cheng, M.M.H. and Lo, S.K. (2010) Teachers' Risk Perception and Needs in Addressing Infectious Disease Outbreak. Journal of School Nursing, 26, 398-406. http://dx.doi.org/10.1177/1059840510375552

[24] IUFM d'Auvergne, University of Limerick and Universidade do Minho (2009) Working Together to Promote Teacher Education in the Field of Health Education and Health Promotion: Position Paper. http://www2.ul.ie/pdf/789339878.doc

[25] Jourdan, D. (2011) Health Education in Schools: The Challenge of Teacher Training. Inpes, coll. Santé en action, France, Saint-Denis. 
Scientific Research Publishing (SCIRP) is one of the largest Open Access journal publishers. It is currently publishing more than 200 open access, online, peer-reviewed journals covering a wide range of academic disciplines. SCIRP serves the worldwide academic communities and contributes to the progress and application of science with its publication.

Other selected journals from SCIRP are listed as below. Submit your manuscript to us via either submit@scirp.org or Online Submission Portal.
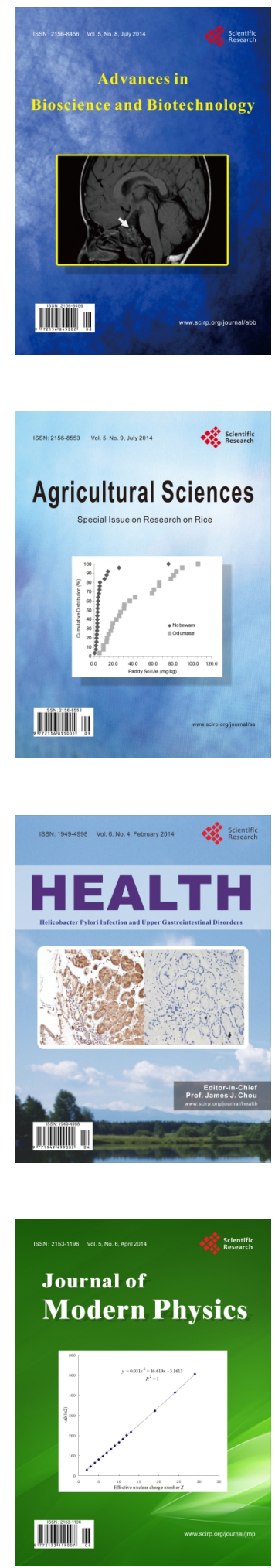
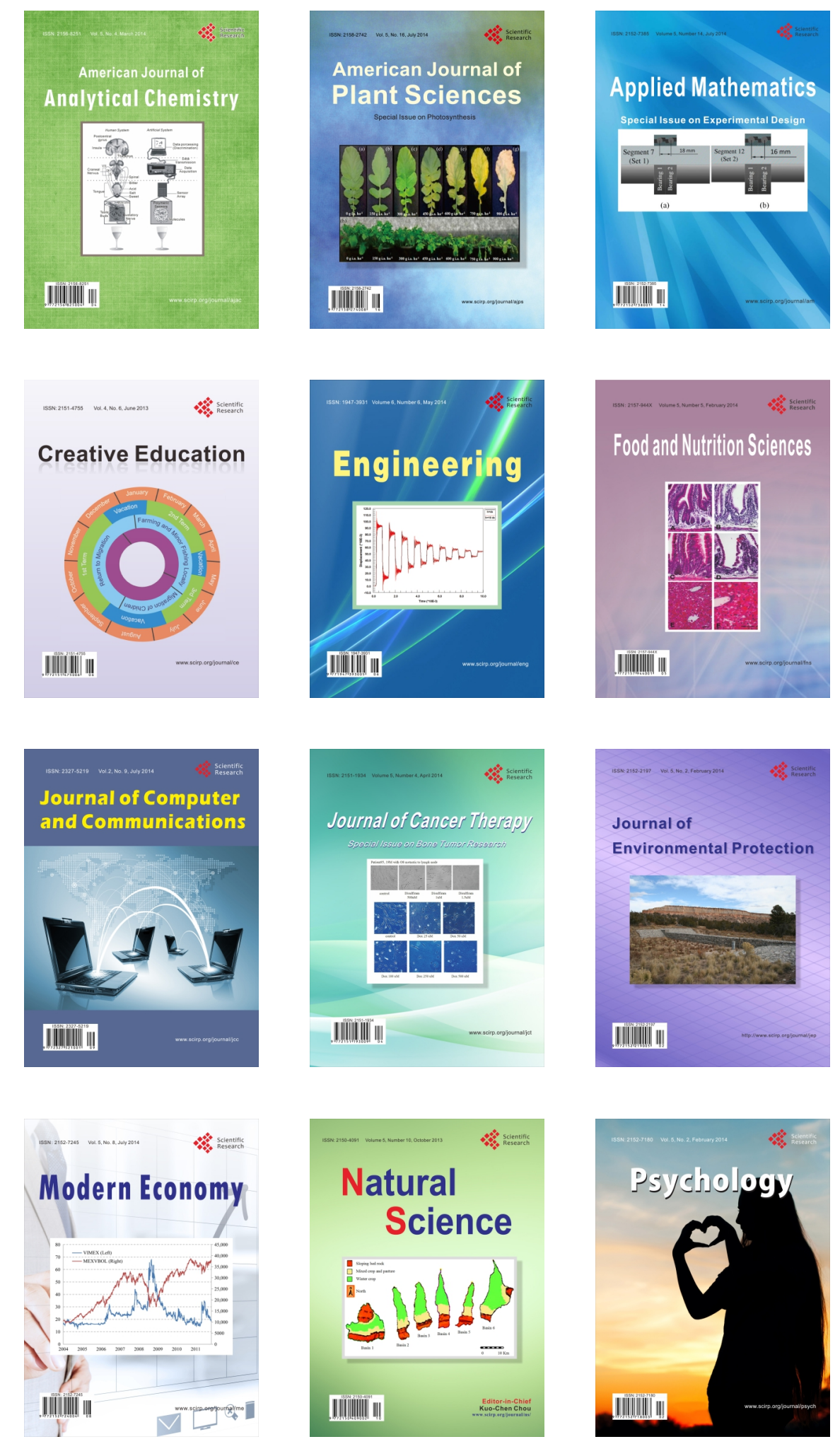